\title{
Assessment of morbidity and mortality of thyroid surgery
}

\author{
Rahman $\mathrm{MM}^{1}$, Rabbani $\mathrm{SMG}^{2}$, Rashid RA ${ }^{3}$, Chowdhury $\mathrm{MA}^{4}$, Nihar F5 ${ }^{5}$ Kamal MS${ }^{6}$. \\ ${ }^{1}$ Dr. Md. Mostafizur Rahman, Junior Consultant, ENT, Sarkari kormachary Hospital, Fulbaria, Dhaka, \\ ${ }^{2}$ Dr. S.M Golam Rabbani, Associate Professor(cc), Department of Otolaryngology \& Head-Neck Surgery, \\ Tairunnessa Memorial Medical College \& Hospital, Board bazar, Gazipur. \\ ${ }^{3}$ Prof. (CC) Dr. Md. Abdur Rashid, Profssor and Head, Department of Ophthalmology, Tairunnessa Memorial \\ Medical College\& Hospital, Board bazar, Gazipur. \\ ${ }^{4}$ Professor Dr. M Alamgir Chowdhury, Professor \& Head of the department of Otolaryngology \& \\ Head-Neck Surgery, Anowar Khan Modern Medical College \& Hospital, Dhaka. \\ ${ }^{5}$ Dr. Fatema Nihar, Assistant Surgeon, Bagra Union Health Sub-center, Shrinogor, Munshigong. \\ ${ }^{6}$ Dr. Mohammad Shah Kamal, Junior Consultant (ENT), Shaheed Samsuddin Ahmed Hospital (Sadar Hospital) Sylhet, \\ *Corresponding Author \\ Date of submission: 10 January 2015 \\ Date of acceptance: 5 May 2015
}

\section{ABSTRACT}

Background: To find out the incidence and types of complications after thyroidectomy.To analyze the factors related to the complications of thyroid surgery.

Material and method: The study was carried out at Shahid Suhrawardy medical college and Hospital, Dhaka from July 2007 to June 2008. Fifty patients were selected for the study who were treated by thyroidectomy. The mean patient's age at the time of surgery was $41.9 \pm 8.1$ years ranged from 10 to 60 years. Data were collected in a prescribed data collection sheet. Then all data were compiled and analyzed.

Result: $12 \%$ of the patients had transient hypoparathyroidism, $4 \%$ had haemorrhage, $2 \%$ had permanent hypoparathyroidism, $4 \%$ had temporary recurrent laryngeal nerve (RLN) palsy and $2 \%$ had permanent recurrent laryngeal nerve palsy. Other rare complications were superior laryngeal nerve palsy, hematoma, and wound infection.

Conclusion: Improved surgical techniques and proper management of complications reduce the postoperative morbidity and mortality of thyroid surgery. In spite of all measures, keen observation in postoperative period is very important to find out the complications for early intervention.

Key word: Thyroidectomy, recurrent laryngeal nerve palsy, hypocalcemia.

\section{Introduction}

Thyroid surgeries are the most common endocrine surgeries performed now a day. This procedure has tremendous evolution to make it a safe surgery. In spite of improved techniques, every thyroid surgeon has come across complications associated with this surgery. This study aims to understand various complications after thyroid surgeries and the factors responsible for complications and discuss management techniques for those complications in brief.

Neoplastic, inflammatory and endocrine abnormalities of the thyroid gland are extremely common affecting approximately $11 \%$ of the general population ${ }^{1}$. Surgery for thyroid gland abnormalities is quite common ${ }^{2}$. Thyroidectomy is one of the commonest operations for the Otolaryngology and Head-Neck Surgeons. Following thyroidectomy complications may develop, these are immediate and AKMMC J 2015; 6(2): 15-19 late complications, such as haemorrhage, dyspnoea, seroma, haematoma, recurrent laryngeal nerve paralysis, thyroid crisis, wound infection and hypoparathyroidism. The complication which is most feared is trauma to the recurrent laryngeal nerve estimated to occur in between 1 and $10 \%$ of operations ${ }^{3-4}$. The nerve may be out, stretched or burnt, usually as a result of failure to recognize or dissect it properly. In unilateral paralysis of the RLN results in immobile vocal cord in the paramedian position which causes weak, cracked and breathy voice. Bilateral paralysis leads to severe airway obstruction necessitating an urgent trachostomy in the majority of patients.

The external laryngeal nerve is traumatized more often than one supposes. Its close relationship to the 
superior vascular pedicle and an occasionally aberrant course predispose it to damage 6 . Diathermy of the small vein which passed from the superior thyroid vein to the lateral part of cricothyroid muscle is a further cause of damage to this nerve. Hypocalcaemia which is uncommon after subtotal thyroidectomy for multinodular goiter may be the result of rough handling of the posterior aspect of the thyroid lobes or interruption of the terminal branches of the main divisions of the inferior thyroid artery. Hypocalcaemia is very common in total thyroidectomy. Intravenous calcium gluconate (10\%) administered slowly provides an immediate solution to the symptoms. Hypothyroidism developing gradually over a period of months or year after operations is a common though acceptable complication of subtotal thyroidectomy and total thyroidectomy and is readily treated with thyroxine ${ }^{7}$.

\section{Material and method}

This prospective study was carried out at Shahid Suhrawardy medical college and Hospital, Dhaka from July 2007 to June 2008. Fifty patients were selected for the study who were treated by thyroidectomy. The mean patient age at the time of surgery was $41.9 \pm 8.1$ years ranged from 10 to 60 years. Data were collected in a prescribed data collection sheet. The data of each patients included age, sex, symptoms, signs, provisional diagnosis, preoperative investigations such as T3, T4, TSH, FNAC, ultrasonogram of thyroid gland, operative notes, histopathological examination and follow up. CT scan was done where indicated. Then diagnosis was confirmed by post-surgical histopathology. Other investigations like total blood count, RBS, FBS, S. creatinine, Urine $\mathrm{R} / \mathrm{M} / \mathrm{E}, \mathrm{ECG}$, chest X-ray were done as routine pre-requisite for operation. Then all data were complied and analyzed. Statistical analysis was done by using appropriate statistical test.

\section{Observation and results}

In this study, we observed haemorrhage in two patients (5\%), right sided vocal cord paresis in two patients, temporary hypothyroidism in one patient and wound infection in one patient. One patient $(2 \%)$ showed transient tetany on 2 nd post operative day which was improved later on. The results are shown in tabulated form below:
Rahman MM, Rabbani SMG, Rashid RA, Chowdhury MA, et al

Table-I: Shows age pattern of the patient.

\begin{tabular}{ccc}
\hline Age in years & No. of Patients & Percentage (\%) \\
\hline $10-20$ & 03 & 06 \\
$21-30$ & 15 & 30 \\
$31-40$ & 17 & 34 \\
$41-50$ & 08 & 16 \\
$51-60$ & 07 & 14 \\
\hline
\end{tabular}

Table-II: Shows sex of the patient among the study group.

\begin{tabular}{ccc}
\hline Sex & No. of Patients & Percentage (\%) \\
\hline Female & 44 & 88 \\
Male & 06 & 12 \\
\hline
\end{tabular}

Table-III: Distribution of age-sex correlation

\begin{tabular}{lcccc}
\hline Age in year & No. of Patients & Female & Male & Female: Male \\
\hline $10-20$ & 03 & O2 & 01 & $2: 1$ \\
$21-30$ & 15 & 15 & 0 & $15: 0$ \\
$31-40$ & 17 & 15 & 02 & $7.5: 1$ \\
$41-50$ & 08 & 07 & 01 & $07: 1$ \\
$51-60$ & 07 & 05 & 02 & $2.5: 1$ \\
Total & 50 & 44 & 06 & \\
\hline
\end{tabular}

Table-IV: Shows distribution of occupation.

\begin{tabular}{lcc}
\hline Occupation & No. of Patient & Percentage (\%) \\
\hline House wife & 38 & 56 \\
Student & 06 & 12 \\
Farmer & 02 & 04 \\
Service holder & 01 & 02 \\
Retired pers on & 01 & 02 \\
\hline
\end{tabular}

Table-V: Types of thyroid disease for which surgery was carried out.

\begin{tabular}{ccc}
\hline Types of Thyroid disease & No. of Patient & Percentage (\%) \\
\hline Solitary nodular goitre & 27 & $\mathbf{5 4}$ \\
Multi nodular goitre & 10 & $\mathbf{2 0}$ \\
Adenomatous goitre & 02 & $\mathbf{0 4}$ \\
Papillary carcinoma withontetastasis & 08 & $\mathbf{0 8}$ \\
Papillary carcinoma withoutmetastasis & 01 & $\mathbf{0 2}$ \\
Follicular carcinoma & 02 & $\mathbf{0 4}$ \\
\hline
\end{tabular}


Assessment of morbidity and mortality of thyroid surgery

Table-VI: Type of surgery among the study group

\begin{tabular}{|c|c|c|c|c|c|c|c|c|}
\hline \multirow[t]{3}{*}{ Diagnosis } & \multirow{3}{*}{$\begin{array}{l}\text { Hemi } \\
\text { thyroidec } \\
\text { tomy }\end{array}$} & \multirow{3}{*}{$\begin{array}{c}\text { Subtotal } \\
\text { c thyroidecto } \\
\text { my }\end{array}$} & \multirow{3}{*}{$\begin{array}{l}\text { Subtotal } \\
\text { thyroidecto } \\
\text { my }\end{array}$} & \multirow{3}{*}{$\begin{array}{c}\text { Total } \\
\text { othyroidect } \\
\text { omy with } \\
\text { neck } \\
\text { dissection }\end{array}$} & \multirow{3}{*}{$\begin{array}{l}\text { Neatotal } \\
\text { thyroidect } \\
\text { my }\end{array}$} & \multicolumn{3}{|c|}{ Excision CompletionTota } \\
\hline & & & & & & oof isthme & is thyroidecto & \\
\hline & & & & & & & my & \\
\hline $\begin{array}{l}\text { Soltary } \\
\text { nodular } \\
\text { goitre }\end{array}$ & 26 & & & & & 01 & - & 27 \\
\hline $\begin{array}{l}\text { Milti } \\
\text { nodular } \\
\text { goitre }\end{array}$ & - & 09 & - & - & 01 & - & - & 10 \\
\hline $\begin{array}{l}\text { Adenomat } \\
\text { ous goitre }\end{array}$ & 02 & - & - & - & - & - & - & 02 \\
\hline $\begin{array}{l}\text { Papillary } \\
\text { carcinoma }\end{array}$ & 03 & - & 05 & 01 & - & - & - & 09 \\
\hline $\begin{array}{l}\text { Follicular } \\
\text { carcinoma }\end{array}$ & - & - & 01 & - & - & & 01 & 01 \\
\hline Total & 31 & 09 & 06 & 01 & 01 & 01 & 01 & 50 \\
\hline
\end{tabular}

Table-VII: Distribution of post operative complications of thyroid surgery

\begin{tabular}{|c|c|c|}
\hline Post operative complications & No. of patients & Percentage $(\%)$ \\
\hline 1. Haemorrhage/Haematoma & 2 & 4 \\
\hline 2. Air way Obstruction & 0 & 0 \\
\hline 3. Recurrent laryngeal nerve & Temporary & 2 \\
\hline paralysis & Persistent & 2 \\
\hline 4. Hypoparathyroidism (Temporary) & 1 & 2 \\
\hline 5. Wound infection & 1 & 2 \\
\hline 6. Thyrotoxic crisis & 0 & 0 \\
\hline Total & 6 & 12 \\
\hline
\end{tabular}

Table-VIII: Mortality after thyroid surgery among the study group

\begin{tabular}{ccc}
\hline Total number of patients & Number of patients expired & Percentage \\
\hline 50 & 0 & $(\%)$ \\
\end{tabular}

\section{Discussion:}

Thyroid surgery is one of the most common endocrine surgeries. The age of the patient at the time of surgery ranged from 10 to 60 years. We observed in our study the maximum incidence is in third and fourth decade. Kasemsewant $\mathrm{L}$ et al5, mentioned in their study that the peak incidence is in fourth and fifth decade.

In this series, out of 50 cases, 44 patients (88\%) were female and 12 patients (24\%) were male, with a female to male ratio was $7.33: 1$. There was a female preponderance in this series but it was higher than that of the study of Kasemsewan L et al5 .The incidence of thyroid diseases were quite higher in female patient in all age group. Regarding occupation of patients, majority of patients $38(76 \%)$ were house wife. Out of 50 patients-6 patients $(12 \%)$ were student, 2 patients (4\%) were cultivator, 2 patients (4\%) were service holder, 1 patient $(2 \%)$ was businessman and 1 patient (2\%) was retired person. Twenty seven patients in this study presented with solitary nodular goiter (54\%), ten patients with multinodular goitre $(20 \%)$, two patients with adenomatous goiter (4\%) and eleven patients with thyroid carcinoma with or without metastasis. Out of eleven patients of thyroid cancer 9 had papillary carcinoma $(81.81 \%)$ and $2(18.19 \%)$ had follicular carcinoma. Out of 9 cases of papillary carcinoma one patient presented with neck node metastasis.

Papillary carcinoma is the commonest thyroid malignancy, constituting 50 percent of all thyroid cancer with a male to female ratio is $1: 36$ and in this series it was much higher $(81.81 \%)$ than that found in standard textbook $(60 \%)$ In this series, commonest thyroid disorder was solitary nodular goiter with an overall incidence of $54 \%$.

Hemithyroidectomy was performed in 31 patients, 26 with solitary nodular goiter affecting one lobe and two patients with adenomatous goiter and three patients with papillary carcinoma. Subtotal thyroidectomy was carried out in 9 patients of multinodular goitre. Total thyroidectomy was done in 6 cases of thyroid cancer and near total thyroidectomy was done in 01 case of multinodular goitre. Isthmusectomy was done in one case of solitary nodular goiter and completion thyroidectomy was done in one case of follicular carcinoma. Total thyroidectomy with modified radical neck dissection was done in one patient of papillary carcinoma with neck node metastasis.

Out of 50 cases, 6 cases (12\%) developed post operative complications. Of these, 2 patients developed post operative hemorrhage. It was due to oozing from remaining thyroid tissue and wound surface which was managed by cauterization with bipolar diathermy after exploration of wound.

During operation, haemorrhage can be avoided by positioning the patient with the neck hyper extended and the head of the operating table elevated at $30^{\circ}$. 
18

AKMMC J $2015: 6(2)$

This positioning provides excellent exposure and reducing cervical venous pressure. Substantial blood vessels in the operative field should be tied with fine silk ligature, whereas small vessels can be managed with the bipolar diatermy ${ }^{7}$. Most surgeons favours the use of a small caliber closed suction drain for the first 24 hours to remove blood and serum from the operative bed.

Khaky et $\mathrm{al}^{8}$, in his study showed that the overall complication rate for combined surgeries was $14.2 \%$ with recurrent laryngeal nerve injury more common than hypoparathyroidism.

In this series 2 patients had unilateral recurrent laryngeal nerve paralysis. Among 2 patients, 01 patient showed gradual improvement of voice in subsequent follow up and after 3 months his voice was almost normal by compensation of the opposite vocal cord. One other patient did not show significant improvement even after an average period of 3 months follow up. Transient paralysis may result from pressure on the nerve by oedema in which cases recovery can be anticipated. Iqbal et $\mathrm{al}^{9}$ found only one recurrent laryngeal nerve damage out of 111 cases of Thyroidectomy (0.9). Lalida et al5, found the incidence of recurrent laryngeal nerve paralysis among 361 patients was $6.09 \%$.

Transient paralysis occurs in about 3 percent of nerve at risk and recovers in 3 weeks to 3 months 2 . The intra-operative nerve monitoring with the purpose of identification of the recurrent laryngeal nerve is a safe and reliable method. Lalida found that, the failure in identifying the nerve did not show significant correlation with incidence of permanent recurrent laryngeal nerve paralysis 5 .

The incidence of hypoparathyroidism is as high as 20 percent when total thyroidectomy and neck dissection is performed and as low as 0.9 percent for subtotal thyroidectomy 6 . But in this series only one patient (2\%) developed transient parathyroid insufficiency on 2nd post operative day which was improved later on.

It is rarely the result of inadvertent removal of all parathyroid gland but more commonly due to disruption of their blood supply. Devascularization can be minimized by careful ligation of branches of inferior thyroid artery on the thyroid capsule distal to their supply of parathyroid glands.

Parathyroid glands usually situated in the posterior border of the thyroid gland but Clark et al ${ }^{12}$ reasoned
Rahman MM, Rabbani SMG, Rashid RA, Chowdhury MA, et al that parathyroid glands situated anterior to the thyroid gland are at highest risk of injury. Injury to the gland during dissection is usually accompanied by a change in colour of the gland from tan to black purple. If the gland is devascularized, it should be removed and minced into $1 \mathrm{~mm}$ slices. After histological verification of parathyroid tissue, the minced gland is auto transplanted into sterno-mastoid muscle or the forearm ${ }^{12}$.

The incidence of hypoparathyroidism is also directly related to the surgeons experience with thyroidectomy. The incidence of permanent hypoparathyroidism following total thyroidectomy ranges from 0.6 to $17 \%$ in reports ${ }^{12,13}$. Bhattacharyy $\mathrm{N}$ et al14 observed in their study, postoperative hypocalcaemia is the most common immediate surgical complication of total thyroidectomy. Out of 50 patients, 01 patient developed wound infection which was managed by exploration and removal of absorbable catgut followed by secondary stitch. There was no death in this series.

\section{Conclusion}

The incidence of major post operative complications like haemorrhage, recurrent laryngeal nerve damage, hypoparathyroidism and also mortality depends on the extent of surgery. The overall incidence of post operative complications in this series was $12 \%$. Out of 50 cases, 2(4\%) patients developed haemorrhage and $2(4 \%)^{\prime}$ patients showed unilateral vocal cord paralysis. One patient showed gradual improvement of voice and recover after 3 months, other patient did not show significant improvement. One patient $(2 \%)$ showed transient tetany on 2 nd post operative day which was improved later on. One patient developed wound infection that healed up on removing the infected catgut followed by secondary stitch.

Surgery of thyroid gland can be performed safely in the majority of patients. A thorough knowledge of potential surgical complications is mandatory for the thyroid surgeon. Successful surgical management of thyroid disease is also based on a sound knowledge of normal and pathologic anatomy and an unhurried, gentle operative technique.

Conflict of interest: We have no conflict of interest. 


\section{Refrences}

01. Mahmood S, Hossain G A, Rahman MU, Khan N and Islam SMM. Awareness of General Population regarding goitre, Mym. Med, Journal 1995; 4(2): 86-91.

02. Conaris GJ, Manowitz NR, MayorG, et al. The Colorado Thyroid Disease Prevalence study. Arch Intern Med, 2000; 160: 526-534.

03. Haward Russell John. "Diagnosis Proceeds Treatment" In : Jk watkinson, Stell and Maran 's Head and Neek Surgery, (4th ed) 459-478.

04. Wade JSH, The morbidity of subtotal thyroidectomy, British Journal of surgery, 1960; 48;'2\$-42;

05. Lalida Kasemsewan M and Shutima Nubthuenetr. Journal of Otolaryngology. 1997: 26 (6); 32-35.

06. Patil PU, Godhi AS, Sant AN. Fine needle aspiration cytology of papillary carcinoma thyroid with Hashimoto 's thyroiditis: Report of two cases. Indian J Pathol microbial 1997; 40: 165-8.

07. Durham C.F, Harrison TS, The surgical anatomy of the superior laryngeal nerve. Surgery Gynecology and Obstetrics, 1964: 118; 38-43.

08. Kahky MD, Weber RS. Complications of Surgery of the thyroid and Parathyroid glands. SurgclinNAM 1993; 73: 307-20.

09. Iqbal M, Rasool MT- Khan M, Malik S, Barkat W. Prospective study of 111 cases of thyroid surgery for postoperative morbidity and mortality. J park Med Assoc. 1989; 39: 201-4.

10. Kumath M; Hussock, Marushci F, Horschig P, Gastinger. Identification of recurrent laryngeal nerve by infraoperative neuromonitoring. 1999; 124 (7): 641-5.

11. Harness JK, Organ CHJ, Thompson NW. Operative experience of US general Surgery residents in thyroid and parathyroid disease Surgery. 1995; 118: 1063-1070.

12. Clark $\mathrm{OH}$, Duh Qy. Primary hyperparathyroidism, a surgical prospective, Endocr Mctabol din N Am 1989; 18: 701 .

13. Hamming JF, Van de velde C.J, Goslings BM. Prognosis and morbidity after total thyroidectomy for papillary, follicular and medullary thyroid cancer. Eur J cancer clin oncol. 1989; 25(9): 1317-23.

14. Bhattacharyy N, Fried MP. Assessment of the morbidity and complications of total thyroidectomy. Arch Otolaryngol head neck surg. 2002: 128(4); 389-92. 